\title{
O POEMA MORRE NO MUNDO: UMA ABORDAGEM DOS RECURSOS LÉXICO- SEMÂNTICOS NA OBRA POÉTICA DE SILVANA MENESES
}

\author{
THE POEM DIES IN THE WORLD: AN APPROACH TO LEXICO-SEMANTIC \\ RESOURCES IN SILVANA MENESES'S POETARY WORK
}

Recebido: 27/10/2021

Aprovado: 08/12/2021

Publicado: 22/12/2021

DOI: $10.18817 /$ rlj.v5i2.2691

Max Mateus Moura da Silva ${ }^{1}$

Orcid ID: https://orcid.org/0000-0001-9022-964X

Marinalva Aguiar Teixeira Rocha

Orcid ID: https://orcid.org/0000-0002-2712-3671

Resumo: Ao construir um texto de teor literário, o autor lança mão de diversos artifícios fornecidos pela língua, de modo a tornar a produção mais expressiva e convidativa. Uma obra adquire feição plural ao ser lapidada em uma perspectiva estética, sensibilizando e cativando potenciais leitores. Dentre esses mecanismos linguísticos, destaca-se o uso feito do léxico que, aliado ao aspecto semântico, possibilita interpretações múltiplas. Desse modo, recorrendo à corrente teórica da estilística, o presente artigo se propõe a analisar os recursos linguístico-expressivos manifestos na produção poética da escritora maranhense Silvana Lourença de Meneses, com foco nos aspectos léxico-semânticos. O estudo encontra-se fundamentado nos trabalhos de Guiraud (1970), Lapa (1998), Monteiro (2009), Rocha (2014), entre outros. A pesquisa selecionou, na obra Embarcação (1988), da referida autora, textos em que se percebe o uso de recursos expressivos de caráter léxico-semânticos na construção dos poemas. Dessarte, tendo como objeto de reflexão tais produções, o estudo evidencia que o uso feito por Meneses explora o potencial linguístico contido no léxico, abarcando também o aspecto semântico.

Palavras-chave: Estilística. Expressividade. Texto literário.

Abstract: While constructing a text with a literary content, the author makes use of several artifices provided by the language, in order to make the text more expressive and inviting. A work acquires a plural aspect when cut in an aesthetic perspective, sensitizing and captivating potential readers. Among these linguistic mechanisms, the use of the lexicon stands out, which, together with the semantic aspect, allows for multiple interpretations. Thus, resorting to the theoretical current of stylistics, this article aims to analyze the linguistic-expressive resources manifested in the poetic production of the writer from Maranhão Silvana Lourença de Meneses, focusing on lexical-semantic aspects. The study is based on studies by Guiraud (1970), Lapa (1998), Monteiro (2009), Rocha (2014) among others. The research selected, in the poem named Embarcação (1988), by the aforementioned author, texts in which the use of expressive resources of a lexical-semantic character in the construction of poems is perceived. Therefore, having as object of reflection such productions, the study shows that the use made by Meneses explores the linguistic potential contained in the lexicon, also embracing the semantic aspects.

Keywords: Stylistics. Expressiveness. Literary text.

\section{Introdução}

\footnotetext{
${ }^{1}$ Acadêmico do Curso de Letras - Português, Inglês e suas Respectivas Literaturas - CESC/UEMA. Bolsista do PIVIC/UEMA. E-mail: max.uemaletras@gmail.com

2 Professora Adjunta do Departamento de Letras do CESC/UEMA. Doutora em História - UNISINOS/RS; Mestre em Letras - UERJ. E-mail: marinalvaat@hotmail.com
} 
A língua é marcada por elementos que a tornam multifacetada. $\mathrm{O}$ uso feito da faculdade da linguagem se realiza em diferentes contextos e com diferentes finalidades. Em uma situação comunicativa cotidiana, por exemplo, o falante recorre ao vocabulário corrente para transmitir uma mensagem de teor utilitário. Doutra sorte, na literatura, a linguagem é aplicada a serviço de um ideal estético (SAMUEL, 1998). Obviamente, isso não significa dizer que o texto literário não possua uma finalidade, mas sim que na sua feitura são trabalhadas várias possibilidades de construção que comportam a noção de estilo.

O texto elabora-se no enlace entre diferentes termos que juntos constroem e adquirem sentidos multiformes. Vocábulos e expressões vinculam-se a outras de maneira estética, tendo assim a sua significação primária alterada. Ao se tratar de uma obra literária, esse fato torna-se ainda mais premente. Uma produção é potencialmente mais sedutora quando consegue vincular forma e conteúdo simultaneamente, de modo a cativar o eventual leitor.

Distintos são os artifícios ofertados pela língua para tornar um texto mais rico, instigante e prazeroso do ponto de vista estético. Ao ponderar acerca das palavras empregadas no discurso casual, é possível notar que algumas, contextualmente, assumem maior significação e sublevam-se sobre outras ao despertar sensações e/ou sentimentos. Isso se observa, com frequência, no manejo do texto literário. $\mathrm{O}$ artista da palavra congrega essas feições do léxico de maneira acurada e diligente no processo criativo (LAPA, 1998).

Sob tal compreensão, a produção literária não emerge desvinculada do plano linguístico, posto que é no efetivo uso da língua, com suas metáforas, jogos de sentido, paradoxos, entre outros, que o texto se constrói e cativa. Portanto, o presente trabalho analisa o caráter expressivo da língua, considerando o aspecto funcional observado na produção poética da escritora Silvana Meneses. Para tanto, buscou-se suporte teórico na Estilística. As reflexões empreendidas decorrem, principalmente, dos estudos de Guiraud (1970), Lapa (1998), Monteiro (2009) e Rocha (2014).

Silvana Lourença de Meneses, nascida em Caxias-MA em vinte e oito de março de 1958, ocupa a cadeira de número 16 (dezesseis) da Academia Caxiense de Letras. Com sua obra de estreia lançada na década de 1980, Meneses discorre em suas produções sobre distintas temáticas, as quais se remetem à cidade natal, a questões sentimentais e amorosas, à infância, entre tantas outras paisagens, ligadas por uma 
linguagem sempre assinalada de pessoalidade. Atualmente, a escritora conta com oito obras publicadas.

O texto de Silvana é permeado de recursos empregados para emocionar e sugestionar interpretações, fazendo com que sua obra proporcione um farto material de análise. Assim, neste trabalho, optou-se por discorrer a respeito dos recursos semânticos e lexicais utilizados pela autora. Dada a amplidão de sua produção e as limitações provenientes da tentativa de sintetizar os resultados, foi selecionada a coletânea Embarcação (1988), a segunda lançada pela escritora.

Importa dizer que o presente estudo é vinculado ao Programa de Iniciação Científica da Universidade Estadual do Maranhão (UEMA), pertencendo ao projeto 'Abordagem dos recursos linguístico-expressivos na obra da escritora Silvana Meneses' (2021-2022). Cabe ressaltar que, embora a proposta propugne uma análise linguístico-expressiva do texto literário [voltado para o aspecto lexical e semântico], não se pretende reduzir o texto ao repasse de normas gramaticais. O que se busca, ao contrário, é partir da forma para o conteúdo, discorrendo a respeito da forma linguística em que a obra literária se sustenta.

Nesse intento, mira-se a língua a partir do pensamento explicitado na tessitura textual. Visando ampliar essa discussão, no tópico a seguir será realizada uma breve síntese dos principais conceitos englobados no estudo. Fundamentalmente, trabalharse-ão as noções de estilo, estilística e estilística léxico-semântica. Posteriormente, dar-se-á a análise linguístico-expressiva dos poemas selecionados.

\section{Pressupostos teóricos: estilo, estilística e estilística léxico-semântica}

Samuel (1998) fornece uma categorização na qual se distinguem dois tipos de textos. O primeiro deles, chamado texto-objeto, é caracterizado por um discurso majoritariamente referencial, sendo o sistema expressivo colocado em espaço secundário. O texto-obra, por sua vez, tem como aspecto distintivo não se reduzir ao teor objetivo, incorporando plurissignificações que atendem a interpretações outras. Dessa forma, o texto literário pode ser classificado como texto-obra por não se limitar a uma relação restrita à funcionalidade comunicativa de interação, primando pelo aspecto estético.

Recuperando o percurso trilhado pela estilística, é, incialmente, necessário elucidar a compreensão que se tem de 'estilo'. Sem comprometimento com nenhuma 
corrente específica da estilística, é possível dizer que o termo reporta a uma "maneira de escrever própria de um escritor" (GUIRAUD, 1970, p. 09). Seguramente, o conteúdo do termo 'estilo' pode ser tomado como algo bem mais vasto, mas, para fins didáticos, tem-se firmada essa definição.

Ao contrapor a linguagem cotidiana e a poética, na perspectiva formalista, Samuel (1998) ressalta que essa preza pela desautomatização, opacidade e por um ideal de perceptibilidade, ao passo que aquela dá-se de modo automático, claro e conceitual. Essa compartimentação pode incorrer em equívocos, considerando que a linguagem cotidiana pode fugir ao que se nomeia como 'claro'. No entanto, "todo textoobra, por não ser meramente discurso, sempre exerce seu vigor criativo" (SAMUEL, 1998, p. 60).

Recai sobre a estilística, enquanto campo de estudo sistemático, a função de estudar a expressão em sua forma potencializada, isto é, na arte da palavra. Guiraud (1970) aponta que a etimologia do vocábulo estilo (stilus) faz concluir que o termo era aplicado para nomear as punções ou estiletes usados para escrever em tabuinhas no período que precedeu a escrita em papel e com a pena. Compreende-se, assim, que é a maneira singular do escritor se expressar para fins literários. A estilística, por sua vez, discorre acerca dos variados meios de construção de estilo (LAPA, 1998).

Como ilustração, tome-se uma palavra qualquer como 'cadeira'. Ao procurar o significado em um dicionário, será possível encontrar algo assim: objeto destinado a assento individual. Essa seria uma definição primária voltada para a representação concreta associada ao termo. É, contudo, possível que o vocábulo se relacione a outras compreensões distintas da citada. Na frase "após vereador ter mandato suspenso, suplente assume uma cadeira na câmara municipal”, é lógico pensar que o termo destacado não encerra a mesma ideia que a apresentada na definição anterior.

Esse simples exemplo, visto de forma casual na interação comunicativa, demonstra que uma palavra abarca acepções que se distinguem a depender do contexto em que é empregada. Na análise expressiva do texto se diria que o uso inusitado do termo, destoante do padrão, seria resultado de uma operação de estilo. Persistindo no exemplo da 'cadeira', ainda se pode assinalar que, mesmo se tomada a sua definição primeira, relacionada ao aspecto físico do objeto, seria possível dizer que existem diferentes tipos de cadeiras (assento). Isto é, existem cadeiras com 
formatos, cores, desenhos, materiais usados na construção diferentes. Essas variações, assim, chamam-se estilos.

$\mathrm{Na}$ comunicação empreendida rotineiramente, as palavras tendem a ser usadas de modo despreocupado com o viés estético (SAMUEL, 1998). O interlocutor, no geral, ao emitir sua mensagem, preocupa-se mais em que esta seja compreendida do que com que seu discurso pareça 'bonito'. É, porém, diferente no uso literário. $\mathrm{O}$ vocabulário é selecionado com finalidades específicas, visando rechear o texto de atributos estéticos (LAPA, 1998). Assentando essa compreensão, Guiraud (1970, p. 11) assinala que a estilística é descrita como "o estudo da expressão linguística".

Ainda na Grécia Antiga já se buscava sistematizar os ditames que regem a arte da expressão linguística. A retórica, uma das três integrantes das artes liberais a compor o tivium ${ }^{3}$, visava atender a esse propósito. Por conta disso, há quem diga que a estilística seja a retórica moderna (GUIRAUD, 1970). De maneira mais ampla, a estilística pode ser entendida tanto como uma ciência da expressão (em suas distintas ramificações) ou como o conjunto de critérios para uma crítica aos estilos individuais (GUIRAUD, 1970).

Assim, a estilística está situada na interface entre o nível linguístico da expressão e o nível literário. A esse respeito, Fiorin (2019, p. 24) é preciso ao afirmar o seguinte:

\begin{abstract}
A linguagem não se presta apenas para informar, influenciar, expressar emoções e sentimentos, criar e manter laços sociais e falar da própria linguagem, ela é também lugar e fonte de prazer. Brincamos com as palavras. Os jogos com o sentido e os sons são formas de tornar a linguagem um lugar de prazer. Divertimo-nos com eles. Manipulamos os vocábulos para deles extrair satisfação. (FIORIN, 2019, p. 24).
\end{abstract}

Como se verifica, a composição literária possui assinalados liames com a esfera linguística. Em especial, incide sobre o léxico grande parcela da expressividade de um texto. De forma correlata, situa-se o aspecto semântico. Nesse estudo, optouse por considerar ambos aspectos durante as análises. A escolha se justifica, pois, conforme assinalado por Rocha (2014), o léxico e o caráter semântico possuem estreita relação, considerando que uma palavra assume maior carga expressiva em decorrência de um sentido adquirido em um contexto específico.

\footnotetext{
${ }^{3}$ Conjunto formada por três disciplinas (gramática, lógica e retórica), as quais eram ensinadas no primeiro estágio acadêmico do período.
} 
Há distintas formas de se expressar uma mesma ideia. Mesmo que cada modo de comunicar um conteúdo carregue pequenas particularidades individuais, é possível externalizar a mensagem com uma gama de palavras que se ajustam ao que se busca exprimir. Para Lapa (1998), o estilo é, em grande medida, manifesto nas possibilidades de escolha executadas. Assim, o literato não se presta somente a comunicar uma informação objetiva. "A escolha de um elemento em vez de inúmeros outros disponíveis no código é uma questão de âmbito estilístico" (MONTEIRO, 2009, p. 99).

Deixando de lado a complexidade que o termo comporta, caso fosse feita uma discussão mais minuciosa, é possível apontar o léxico como o conjunto de palavras que um falante dispõe em seu vocabulário para produzir um discurso, seja ele oral ou escrito. Operam-se diversificadas aplicações feitas pelos usuários de uma língua com o léxico. Ocasionalmente, o falante pode recorrer ao uso de neologismos e/ou empréstimos vocabulares, por exemplo, para suprir uma carência de material linguístico (ROCHA, 2014).

Nessa esteira, "o léxico opera semanticamente ao estar vinculado à sinonímia, à polissemia, à homonímia", uma vez que esses fenômenos permitem à palavra novos valores (ROCHA, 2014, p. 69). Portanto, a semântica pode ser tomada a atribuição de sentido dada a um termo ou expressão, ou seja, ao campo do significado. (MONTEIRO, 2009). É relevante mencionar que, para Ullmann (1964, p. 438, apud ROCHA, 2014, p. 70), "de entre todos os artifícios linguístico possíveis, a mudança do significado é o mais simples, o mais discreto e talvez o mais elegante [...]".

Em certo sentido, a língua estabelece conceitos por meio dos quais a realidade é organizada. Por intermédio dessa atividade simbólica que atrela significados a palavras, são exprimidos diferentes modos de compreender o mundo (FIORIN, 2019). Sobre esse tópico, Lapa (1998) adverte que o simples entrelace arbitrário de sinônimos denuncia um escritor aprendiz, pois o efeito estilístico perde-se ao, tão somente, considerar expressões distintas como plenamente iguais ao comunicar um sentido.

O jogo semântico envolve possibilidades de interpretações conferidas a um termo em decorrência da aplicação que dele é feita. Por exemplo, ao se observar a etimologia de algumas palavras, verifica-se que muitas tiveram o seu sentido primário ampliado, passando a envolver outras acepções. Em tais casos, a significação só poderá ser aferida se considerado o contexto comunicativo. 
É oportuno apontar, então, que a estilística léxico-semântica se aplica à análise da palavra em seu contexto, ligada aos seus componentes semânticos (ROCHA, 2014). Portanto, ao selecionar textos para uma análise linguístico-expressiva, é preciso escolher autores que explorem o léxico em suas variadas aplicações, permitindo leituras não circunscritas ao previsível.

\section{Análise dos recursos léxico-semânticos}

Como mencionado, optou-se por abordar os aspectos léxico-semânticos da poesia de Silvana Meneses, pois, embora a autora detenha uma produção significativa e componha a Academia Caxiense de Letras, não se percebeu, ainda, estudos detidos a respeito de sua obra. De modo a tornar possível o levantamento dos traços linguístico-expressivos na obra Embarcação ${ }^{4}$, serão apresentados, integralmente, alguns dos poemas que compõe a coletânea.

\section{Poesia (P1)}

Ela me põe pra cima me vira de cabeça para baixo realça a vida e se me dá emocionada. (p. 03)

\section{Lembrança (P2)}

Saudade chuva às vezes vem de mansinho outras vezes não.

Se arreia toda desarruma tudo o que pensava estar no seu devido lugar. De repente para tudo.

É só uma gota que não incomoda mais. (p. 4)

\section{Meia vida (P3)}

O poema está por aí correndo do dia rondando a noite

noite mágica

de fragmentos de gente

que fazem vida.

O poema morre no mundo, em mim

Como uma pálida inspiração. (p. 6)

\section{Real (P4)}

Lua cheia no meio da noite tenho sempre o mesmo frenesi e me pergunto que cio é esse.

Quarto minguante olho a cama descansada de ti à espera da tua crescente loucura em mim. (p. 7)

\section{Paciência (P5)}

No balanço das ondas o vai e vem.

No balanço das ondas tu que vais

\footnotetext{
${ }^{4}$ Considerando que todos os textos de Silvana Meneses utilizados neste trabalho estão presentes na coletânea Embarcação, optou-se por apontar somente as páginas nas quais cada poema pode ser encontrado. Também se optou por nomear os poemas como: P1, P2, P3, P4, P5, P6, P7 e P8, onde P significa poema e o número remete à ordem em que o texto é apresentado. Tal código servirá para apontar, na análise em sequência, de qual poema foi extraído o excerto considerado.
} 
e não vens. (p. 8)

\section{Brincadeira (P6)}

Na ciranda da vida

A tua saia rodada me chama

Escondo-me por baixo das tuas cores,

Me entrelaço com teus passos,

Danço a tua malícia

E deixo a roda girar, girar... (p. 11)

Cotidiano (P7)

Amanhecemos.
Ainda é escuro.

Nada de clarear, clareando.

O sol não bate nas nossas janelas.

Esse lugar é um breu. (p. 12)

Recomeçar (P8)

A esperança deixou de sonhar recolheu-se.

A realidade ficou nua.

Dormem todas as alegrias, emoções.

Agora a poesia sairá na noite

desvendando-lhe os olhos

sonhando com seu novo rosto. (p. 21)

Inicialmente, ao considerar a obra de Meneses, observa-se que seus poemas são construídos por versos breves e de linguagem direta. A obra Embarcação, sendo a segunda da escritora, desvela as nuances de um estilo próprio que começava a se desenhar. Em obras ulteriores, é possível notar que a poeta não mais intitula os poemas. Os títulos dados às composições são, portanto, nesse primeiro estágio do fazer poético da autora, elementos fundamentais para conferir expressividade aos textos.

Dessa forma, os títulos aplicados podem ser tomados como recursos semânticos, pois delimitam uma compreensão que se busca no poema (ROCHA, 2014). Por tal motivo, nesse momento do fazer poético de Silvana Meneses, algumas produções tornam-se obscuras ou vagas quando os títulos são desconsiderados. Como ilustração, cita-se "Poesia" (P1). A autora aponta os enlevos causados pela poesia, porém, no interior do texto, sequer menciona essa palavra. Logo, a compreensão se torna concreta somente na leitura do título. Em "Lembrança" (P2) e "Brincadeira" (P6), nota-se que é feita uma metáfora para simbolizar, respectivamente, o processo de esquecer algo ou alguém e o momento em que se conhece uma nova pessoa.

"Paciência" (P5), "Cotidiano" (P7) e "Recomeçar" (P8) seguem caminhos parecidos, visto que servem como síntese para o conteúdo das composições. Enquanto "Paciência" narra o relato de alguém a esperar (pacientemente?) o outro retornar, "Cotidiano" apresenta o caráter cíclico da vida. "Recomeçar", por sua vez, envolve a potencialidade da poesia em apresentar outros caminhos quando a realidade mostra-se lacerante. 
Entre os oito poemas selecionados para análise se constata uma característica marcante também presente no restante da coletânea. Essencialmente, os títulos dados aos textos condensam seu conteúdo. A obra de Silvana é extremamente influenciada pela estética Haikai ${ }^{5}$, o que acaba se refletindo nas operações lexicais e semânticas. Herdando alguns aspectos provenientes do Haikai, os poemas se dão em sentenças que se encadeiam, aparentemente, sem uma evidente relação lógica direta. Contudo, os últimos versos de cada poema costumam estabelecer o espaço semântico e conferir sentido ao todo. No poema "Recomeçar" (P8), por exemplo, o verso "sonhando com seu novo rosto" serve como justificativa para o recomeço apontado no título.

Lapa (1998) registra que o uso de vocábulos em contextos que destoam da aplicação habitual vale como meio de tornar o texto mais permeado de expressividade, além de realçar o ludismo verbal. A poeta, portanto, trabalha terminologias inusitadas ao justapor palavras, o que também propicia que um novo sentido surja ao vincular os termos (ROCHA, 2014). Observa-se esse recurso em: "Saudade chuva" (P2), onde aspectos da chuva são usados para representar a saudade, e em "Quarto minguante" (P4), em que o termo 'minguante' direciona a uma das fases da lua em que a sombra do astro projetada na Terra diminui, assim como o quarto 'mingua' pela ausência da pessoa querida.

Outro importante recurso manifesto é a gradação. Rocha (2014) aponta que a sequência de palavras postas serve como recurso estilístico ao manifestar uma cadência de importância ou mesmo sentimentos do eu lírico. Em: "Amanhecemos. / Ainda é escuro. / Nada de clarear, clareando. / O sol não bate nas nossas janelas. / Esse lugar é um breu." (P7) é posta uma sequência lógica. A gradação é reforçada pelo ponto ao final de cada verso, o que encerra um sentido de completude no que é dito. Isto é, quando se diz 'amanheceu', o termo possui significação completa, como se um ciclo (do cotidiano) tivesse sido concluído.

As antíteses são também responsáveis por impor ao texto de Meneses significativo valor expressivo. O uso de palavras de sentidos contrários permite submergir em espectros diametralmente opostos de uma realidade (MONTEIRO, 2009). Nota-se no uso feito no P1 "cima" / "baixo" que a antítese pretende explicitar

\footnotetext{
${ }^{5}$ Haikai é um tipo específico de poesia de origem japonesa. No geral, os poemas são escritos em três versos, o que acaba por instigar a busca pelo que é mais essencial no poema, de modo a atingir a máxima concisão.
} 
os diferentes extremos proporcionados pela poesia. Efeito similar é evocado no uso "dia" / "noite" e "vida/ "morre" (P3), valendo para afirmar que o poema supera a dimensão temporal e metafísica da existência, indo do dia à noite e da morte à vida.

Já a antítese "vai/ vem" (P5) ressalta a frustração do eu lírico pelo fato de a pessoa querida não ter retornado. Essa linguagem é contraposta à imagem do balanço das ondas, que "vai e vem". Todavia, é dito que o tu a quem o poema faz menção "vai", mas não "vem". Assim, é perceptível que o emprego feito dos termos resulta em certa carga sentimental, que pode ser compreendida como uma tristeza e/ou frustração por não ver a pessoa retornar.

Considerada por alguns como a principal figura de linguagem, a metáfora em muito pesa para enriquecer o texto no seu teor semântico. Em essência, a metáfora é usada para deslocar um termo de um uso habitual e aplicá-lo em um contexto distinto, tendo, porém, algum elemento que justifique o novo uso feito (LAPA, 1998). O texto de Silvana recorre frequentemente a esse recurso. Menciona-se os termos: "chuva" (P2), usado para simbolizar a lembrança, pois, de início, pode surgir de forma intensa, mas aos poucos vai sendo aplacada, passando a ser "só uma gota/ que não incomoda mais" (P2); "lua" (P4), onde se vincula o astro à relação minguante (fase da lua) com a pessoa amada, ao passo que se torna crescente (fase da lua) a saudade; além das outras metáforas já citadas e que se evidenciam nos títulos dos poemas.

A autora recorre também ao paradoxo para instigar o leitor a participar do texto. Ao valer-se de ideias contraditórias em um mesmo poema, o léxico é explorado em sua potencialidade, ao passo que o valor semântico se amplia ao romper com a linearidade e com o óbvio. Quando é dito "Amanhecemos." (P7), espera-se, pelo fato de o amanhecer se relacionar com o nascimento do sol, que esteja claro, mas o eu lírico ressalva, "Ainda é escuro. / Nada de clarear, clareando. / O sol não bate nas nossas janelas. / Esse lugar é um breu." (P7).

Pode, ainda, ser citado o uso feito de alegorias. Nas palavras de Rocha (2014, p. 97), a alegoria é um recurso que "consiste na sucessão de textos metafóricos em um enunciado, produz efeitos inusitados, tornando mais compreensível o poético". A exemplo, tem-se "correndo do dia/ rondando a noite/ [...] de fragmentos de gente" (P3); "A tua saia rodada me chama" (P6); "O sol não bate nas nossas janelas." (P7); "A esperança deixou de sonhar / [...] A realidade ficou nua. / Dormem todas as alegrias, emoções. / Agora a poesia sairá na noite 
/ desvendando-Ihe os olhos /sonhando com seu novo rosto." (P8). Por ser uma linguagem dotada de simbolismo, a alegoria "evoca sensações intensas, revigorando e potencializando o conteúdo linguístico que se deseja ressaltar" (ROCHA, 2014, p. 97).

\section{Considerações Finais}

Este trabalho buscou realizar uma análise linguístico-expressiva da obra Embarcação (1988), de autoria da poeta Silvana Meneses, com ênfase nos aspectos léxico-semânticos. Por meio do estudo foi possível notar que uma produção literária se torna envolvente à medida que aplica os recursos estéticos ofertados pela língua. Ao contrário de um amontoado de frases meramente justapostas, o texto é uma produção resultante de escolhas operadas por um autor de maneira consciente.

Meneses, ao construir os poemas, recorre aos mecanismos linguísticos para permear suas obras de expressividade. Sua produção reflete a forma atenta de trabalhar o léxico, explorando o jogo verbal e de sentidos decorrentes do uso feito do signo linguístico. Ao passo que seus poemas carregam elementos que evocam a sensibilidade, a profusão de efeitos léxico-semânticos instiga o leitor a procurar sentidos em seus versos. A linguagem direta em que se apresentam favorece 0 diálogo com o interlocutor, estabelecendo uma relação de proximidade.

Com o presente trabalho, portanto, evidenciou-se a necessidade de abordar os elementos expressivos presentes em textos literários. É válido apontar que não se pretende reduzir a literatura a uma plataforma para estudos de teor gramatical, mas elucidar que a produção poética se realiza na língua, sendo preciso observar o estudo linguístico e literário de maneira integrada. Assim, a língua torna evidente a sua recursividade ao ser explorada de modo inusitado por aqueles que dominam a arte da palavra poética.

Por fim, salienta-se que, ao tentar analisar os recursos linguístico-expressivos presentes no corpus da pesquisa, é possível ter ocorrido alguma omissão ou simplificação decorrente do esforço por sintetizar os resultados. Portanto, a análise aqui realizada não encerra as possibilidades de leitura, sendo, ainda, necessárias outras formas de considerar a obra de Silvana Meneses em sua pluralidade. Ademais, a produção da escritora oferta uma ampla gama de estudos possíveis. 


\section{Referências}

FORIN, José Luiz. A linguagem humana: do mito à ciência. In.: FORIN, José Luiz. (Org.) Linguística? Que é isso? São Paulo: Contexto, 2019.

GUIRAUD, Pierre. A Estilística. Tradução de Miguel Maillet. São Paulo: Mestre Jou, 1970.

LAPA, Manuel Rodrigues. Estilística da Língua Portuguesa. 4ª ed. São Paulo: Martins Fontes, 1998.

MONTEIRO, José Lemos. A estilística: manual de análise e criação. $2^{\underline{a}}$ ed. PetrópolisRJ: Vozes, 2009.

MENESES, Silvana Lourença de. Embarcação. [s.I.]: [s.n.], 1988.

SAMUEL, Rogel (Org.). Manual de Teoria Literária. 11ํㅡㄹ ed. Petrópolis, RJ: Vozes, 1998.

ROCHA, Marinalva Aguiar Teixeira. A expressividade em Ana Maria Machado e José Paulo Paes: uma proposta para motivar a leitura. Curitiba: Appris, 2014. 